\title{
Akut Kısa Süreli Selenyum Tedavisi: Akut Böbrek Hasarında Kurtarıcı Bir Tedavi Olabilir mi?
}

\author{
Acute Short-Term Selenium Treatment: Could It Be a Salvage \\ Therapy in Acute Kidney Injury?
}

\author{
Aysel TAKTAK ${ }^{1}$, Umut Selda BAYRAKÇI ${ }^{2}$, Esra KARAKUŞ ${ }^{3}$, Banu ÇELIKEEL ACAR ${ }^{4}$, Adem KÖKSOY5, \\ Murat ALIŞIK ${ }^{6}$, Salim NEŞELIOĞLU6 ${ }^{6}$ Özcan EREL ${ }^{6}$
}

\author{
${ }^{1}$ Mustafa Kemal Üniversitesi Tıp Fakültesi, Çocuk Nefroloji Bölümü, Hatay, Türkiye \\ ${ }^{2}$ Yıldırım Beyazıt Üniversitesi, Tıp Fakültesi, Çocuk Sağlığı ve Hastalıkları, Çocuk Nefrolojisi, Ankara, Türkiye \\ ${ }^{3}$ Ankara Şehir Hastanesi, Patoloji Kliniği, Ankara, Türkiye \\ ${ }^{4}$ Ankara Şehir Hastanesi, Çocuk Hastanesi, Çocuk Romatoloji Kliniği, Ankara, Türkiye \\ ${ }^{5}$ Sağlık Bilimleri Üniversitesi, Van Eğitim ve Araştırma Hastanesi, Van, Türkiye \\ ${ }^{6}$ Yıldırım Beyazıt Üniversitesi, Tıp Fakültesi, Biyokimya Bilim Dalı, Ankara, Türkiye
}

\begin{abstract}
Öz
Amaç: İskemi/Reperfüzyon (IR) hasarı nativ ve nakil böbrekte akut böbrek hasarının önemli bir nedenidir. Bu durum oksitadif bir ortam oluşturarak doku hasarına neden olur. Bu çalışmanın amacı kısa süreli akut selenyum (Se) tedavisinin oksidatif durum ve akut böbrek hasarına etkilerini değerlendirmektir.

Gereç ve Yöntemler: Bu çalışmada 18 yetişkin Long Evans cinsi rat rastgele 3 gruba ayrıldı. Genel anestezi altında steril koşullarda batın insize edildi, bilateral böbrek damar yapıları ayrıldı. Sol renal arter klemplendi, sağ nefrektomi yapıldı, 45 dakika iskemi uygulanmasını takiben sol renal arter klempi açıldı ve 4 saat reperfüzyon uygulandı. IR ve Se tedavisi grubuna, cerrahi ișlemden 4 saat önce ve reperfüzyon periyodunun bitiminden 4 saat sonra 0.625 mg/kg Se oral verildi. IR grubuna benzer protokol ile 1 cc steril salin oral uygulandı. Sham grubu dışında tüm ratlar ikinci ilaç uygulamasından 4 saat sonra sakrifiye edildi. Kan ve doku örnekleri alınarak histopatolojik değerlendirme ve kan kreatinin, total thiol, nativ thiol, disülfid düzey ve dinamik thiol/disülfid oran ölçümleri yapıldı.
\end{abstract}

Bulgular: Selenyum tedavisi alan grupta İR hasarı öncesi ve sonrası thiol düzeylerinde anlamlı azalma görülmezken iR grubunda thiol düzeyinde anlamlı düşme gözlendi ( $p=0.345, p=0.028$ ). Selenyum tedavisi alan ve almayan gruplar böbrek fonksiyonları ve histopatolojik açıdan karşılaştıııdığında Se tedavisi alan ratlarda anlamlı iyileşme saptanmadı $(\mathrm{p}=0.053)$.

Sonuç: Kısa süreli akut Se tedavisi hücrenin oksidatif durumunu düzeltmekle birlikte bu durum histopatolojik ve biyokimyasal iyileşme için yetersizdir. Ayrıca halihazırda hasarlı böbrekte Se tedavisinin mevcut durumu kötüleştirdiği düşünülmektedir.

Anahtar Sözcükler: Akut böbrek hasarı, İskemi/Reperfüzyon hasarı, Kurtarıcı tedavi, Oksidatif stres, Selenyum

\section{ABSTRACT}

Objective: Ischemia/Reperfusion (IR) injury is an important cause of acute kidney injury (AKI) in native and transplanted kidneys. This condition aggravates tissue damage by initiating an oxidative status. This study evaluates the effect of acute short-term selenium (Se) treatment on oxidative status and acute kidney injury.

(1)

TAKTAK A

BAYRAKÇI US

KARAKUSE

CELIKEL ACAR B

KÖKSOY A

ALIŞIKM

NEȘELIOĞLU S

EREL Ö
0000-0001-7724-9160 $0000-0002-5301-2617$ $0000-0002-6592-4533$ 0000-0002-1808-3655 (0000-0002-1808-3655 (0000 :0000-0003-0434-3206 0000-0002-0974-5717 0000-0002-2996-3236
Çıkar Çatışması / Conflict of Interest: Tüm yazarlar adına, ilgili yazar çıkar çatışması olmadığını belirtir

Etik Kurul Onayı / Ethics Committee Approval: Bu çalıșma Helsinki Deklarasyonu Illkelerine uygun olarak yapılmıștır. Bu çalıșma, Gazi Üniversitesi hayvan deneyleri yerel etik kurulunca onaylandi (66332047-604.01.02-3).

Yazarların katkısı / Contribution of the Authors: TAKTAK A: Araştırma ve/veya makalenin hipotezini veya fikrini oluşturan, Sonuçlara ulaşmak için planlama/metodoloji belirleme, Hasta takibinde sorumluluk almak, ilgili biyolojik malzemelerin toplanması, veri yönetimi ve raporlama, deneylerin yürütülmesi, Sonuçların mantıksal olarak yorumlanması ve sonuçlandırılması, Çalışma için gerekli literatür taramasında sorumluluk almak, Çalışmanın bütününün veya önemli bölümlerinin yazımında sorumluluk almak. BAYRAKÇI US: Sonuçlara ulașmak için planlama/metodoloji belirleme, Araștıma/ çalıșmanın sorumluluğunu üstlenmek, ilerlemenin seyrini denetlemek, Hasta takibinde sorumluluk almak, ilgili biyolojik malzemelerin toplanması, veri yönetimi ve raporlama, deneylerin yürütülmesi, Çalıșmanın bütününün veya önemli bölümlerinin yazımında sorumluluk almak, Yazım ve dilbilgisi dıșında yönetimi ve raporlama, deneylerin yürütülmesi, Çalıșmanın bütününün veya önemli bölümlerinin yazımında sorumluluk almak, Yazım ve dilbilgisi dıșında
bilimsel olarak gönderilmeden önce makaleyi gözden geçirme KARAKUŞ E: Hasta takibinde sorumluluk almak, ilgili biyolojik malzemelerin toplanması, veri yönetimi ve raporlama, deneylerin yürütülmesi. ÇELIKEL ACAR B: Araştırma/ç̧alışmanın sorumluluğunu üstlenmek, ilerlemenin seyrini denetlemek, , Yazım ve dilbilgisi dıșında bilimsel olarak gönderilmeden önce makaleyi gözden geçirme. KÖKSOY A: Sonuçların mantıksal olarak yorumlanması ve sonuçlandırılması, Çalışma için gerekli literatür taramasında sorumluluk almak. ALIŞIK $\boldsymbol{M}$ : Hasta takibinde sorumluluk almak, ilgili biyolojik malzemelerin toplanması, veri yönetimi ve raporlama, deneylerin yürütülmesi. NESELiOĞLU S: Hasta takibinde sorumluluk almak, ilgili biyolojik malzemelerin toplanması, veri yönetimi ve raporlama, deneylerin yürütülmesi. EREL Ö: Hasta takibinde sorumluluk almak, ilgili biyolojik malzemelerin toplanması, veri yönetimi ve raporlama, deneylerin yürütülmesi, Sonuçların mantıksal olarak yorumlanması ve sonuçlandırılması.

Atıf yazım șekli / How to cite : Taktak A, Bayrakçı US, Karakuș E, Çelikel Acar B, Köksoy A, Alșık M ve ark. Akut Kısa Süreli Selenyum Tedavisi: Akut Böbrek Hasarında Kurtarıcı Bir Tedavi Olabilir mi?. Türkiye Çocuk Hast Derg 2022;16:210-214.
Yazışma Adresi / Correspondence Address:

\section{Aysel TAKTAK}

Mustafa Kemal Üniversitesi Tıp Fakültesi, Çocuk Nefroloji Bölümü, Hatay, Türkiye

E-posta: aysel.taktak@gmail.com
Geliş tarihi/ Received : 02.05.2021 Kabul tarihi / Accepted : 16.06.2021 Elektronik yayın tarihi $\quad: 27.09 .2021$ Online published

DOI: 10.12956/tchd.931486 
Material and Methods: A total of 18 adult male Long Evans rats were randomly allocated into three groups. Under general anaesthesia and sterile conditions, the anterior abdominal wall was incised, and bilateral renal vessels were separated. Left renal artery was clamped, right nephrectomy was performed after 45 min of ischemia, left renal artery was de-clamped, and 4 hours reperfusion was performed. In IR and Se treated group, $0.625 \mathrm{mg} / \mathrm{kg}$ Se was administered orally 4 hours before the surgical procedure and 4 hours after the reperfusion period. In the IR group, one cc sterile saline was given orally with a similar protocol. All rats except the sham group were sacrificed after 4 hours following the second dose of saline and Se administration. Blood samples and kidney saved for histopathological investigation and creatinine, total thiol, native thiol, disulfides levels and dynamic thiol/disulfide ratio determinations.

Results: While there was no significant decrease in thiol levels before and after IR injury in the Se treated group, a significant decrease was observed in the IR group ( $p=0.345, p=0.028$ ). There was no statistically significant improvement when the groups were compared in terms of renal functions and histopathological evaluation $(p=0.053)$.

Conclusion: Our study revealed that acute short-term Se treatment improves the kidney redox status. However, histopathological changes in kidney and plasma creatinine levels remain unaffected. Moreover, Se administration increases the existing kidney damage after the injury has occurred.

Key Words: Acute kidney injury, Ischemia-reperfusion injury, Oxidative stress salvage therapy, Selenium

\section{GiRiş}

İskemi/Reperfüzyon hasarı (IR) kanlanması azalan bir organda perfüzyon ve oksijenizasyonun yeniden sağlanması ile gelişen hasardır. Başta enfeksiyonlar, enfarktüs ve organ nakli olmak üzere çeşitli klinik durumlar IR hasarına neden olabilir. IR hasarı temelde reaktif oksijen radikallerinin ( $\mathrm{rOR}$ ) tetiklediği inflamatuar bir süreçtir (1). Reaktif oksijen radikalleri hücre zarı lipitleri, lipoproteinler ve nükleik asitler ile etkileșerek hücre yapı ve fonksiyonlarının bozulmasına nihayetinde hücre hasarına yol açar (2). Doku ve organları oksidatif hasarın etkilerine karşı koruyacak bir çok endojen mekanizma mevcuttur. Bu endojen antioksidan mekanizmalar, süperoksit dismutaz (SOD), glutatyon peroksidaz (GP), katalaz gibi enzimatik ve glutatyon, melatonin, serüloplazmin, transferin gibi non-enzimatik bileșenlerden oluşur $(3,4)$. Thioller $(\mathrm{RSH})$ karbon atomuna bağlı sülfidril grubu $(-\mathrm{SH})$ içeren organik yapılardır. Organizmada bulunan total thiol hücre içi ve hücre dışında serbest thiol veya glutatyon formunda iken, dolaşımda büyük oranda albümine bağlıdır (5). Thioller oksidanlar ile reaksiyona girerek disülfid bağları (RSSR) oluşturur ve tekrar indirgenerek thiol gruplarına dönüşür. Dinamik thiol-disülfid dengesi olarak tanımlanan bu çift yönlü reaksiyon hücrenin redoks durumunun önemli göstergelerinden biri olup glutatyon peroksidaz ve glutatyon redüktaz ile sağlanır (6). Selenyum (Se) glutatyon peroksidazın yapısında bulunur, bu bakımdan vücudun anti-oksidan savunma mekanizmalarında son derece önemli bir eser elementtir (7).

Çalışmamızda IR ilișkili böbrek hasarı oluşturulan ratlarda akutkısa dönem Se tedavisinin böbrek fonksiyonları, hücre redoksu ve histopatolojik değişiklikler üzerine olan etkisi değerlendirildi.

\section{GEREÇ ve YÖNTEMLER}

Bu çalışma ağırlıkları 250-300 gr olan Long Evans türü 18 erişkin erkek rat üzerinde yapıldı. Tüm ratlar aynı ortamda, sabit sıcaklıkta $\left(20 \pm 2^{\circ} \mathrm{C}\right), 12$ saatlik aydınlık/karanlık döngüsünde, musluk suyu ve yiyeceklere serbest erişimin olduğu ad Libitum beslenme koşullarında muhafaza edildi.
Ratlar eşit sayıda 3 gruba ayrıldı. Genel anestezi altında, steril koșullarda karın ön duvarı orta hattan insizyon ile açıldı, bilateral böbrek damarları kör disseksiyon ile ayrıldı, atravmatik klemp ile sol böbrek kan akımı kesildi. İskemi böbrek renginde koyulașma olarak gözlendi (Şekil 1). Sağ nefrektomi uygulandı. Sol böbrek klempi 45 dk sonra açıldı, böbreğin tekrar kendi rengine dönmesiyle reperfüzyon izlendi, 4 saat reperfüzyon uygulandı. İskemi/Reperfüzyon grubuna cerrahi prosedürden 4 saat önce ve 4 saatlik reperfüzyon periyodunun bitiminden 4 saat sonra $0.625 \mathrm{mg} / \mathrm{kg}$ Se (Selenometionin $100 \mathrm{mcg} / 100$ tablet, Solgar) oral olarak verildi (IR/Se grubu). Kontrol grubunda IR/ Se grubuna benzer cerrahi işlemler uygulandı, işlem öncesi ve sonrasında $1 \mathrm{cc}$ steril salin oral olarak verildi (IR/0 grubu). Sham grubuna benzer cerrahi prosedür uygulandı, ancak sol renal ven klemplenmedi ve sağ nefrektomi yapıımadı. Batın steril kapatıld.

Tüm cerrahi prosedür, ratlarda optimal vücut ısısını koruyacak şekilde ısıtımış masa üzerinde steril teknikle uygulandı. Genel anestezi intra müsküler Xylazine (5 mg/kg/doz) ve Ketamin (45 $\mathrm{mg} / \mathrm{kg} / \mathrm{doz}$ ) ile sağlandı.

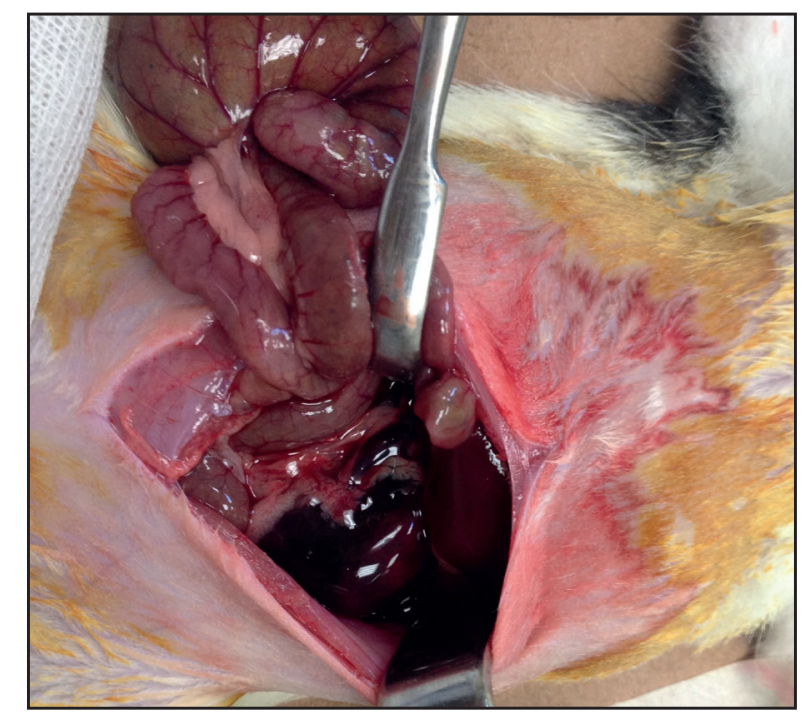

Şekil 1: İskemik sol böbrek 
Sham grubu dışında, tüm ratlar cerrahi prosedürün 12. saatinde (ikinci ilaç dozunun 4. saatinde) sakrifiye edildi. Deney bitimi tüm ratlardan kan ve doku örnekleri alınarak, kan kreatinin, total thiol, nativ thiol, disülfid düzey, dinamik thiol/disülfid oran ölçümleri ve histopatolojik değerlendirme yapıldı.

Her rattan iki kanörneği elde edildi. Illkkanörneğicerrahi prosedür öncesi kuyruk arterinden alındı. Takiben ilaç uygulamaları yapıldı. Ikinci kan örneği sakrifikasyon sırasında genel anestezi altında intrakardiyak alındı. Kan kreatinin düzeyleri böbrek fonksiyon göstergesi olarak kabul edildi. Total thiol, nativ thiol, disülfid, dinamik thiol/disülfid oranları hücrenin oksidatif durumunun tespitinde kullanıldı. Dinamik thiol/disülfit oranı Erel ve ark. (8) yeni tanımlamış olduğu yöntem ile değerlendirildi.

Nefrektomi materyali, standart formalin fiksasyonu ve parafin gömme ile hazırlandı, $5 \mu \mathrm{m}$ kalınlı̆ındaki doku örnekleri hemotoksilen-eozin ile boyandı. Böbrek hasarı; renal tübüler ödem, tübüler dilatasyon, konjesyon, tübüllerde silendir oluşumu, epitel hücre nekrozu görülmesi olarak tanımlandı. Her örnek x400 büyütme altında en az 20 ayrı noktadan değerlendirildi. Bulgular normal (-), hafif $(+)$, orta $(++)$, ciddi $(+++)$ olarak Korkmaz ve ark. (9) yapmış oldukları çalışmayla benzer şekilde derecelendirildi. Bu çalışma Gazi Üniversitesi hayvan deneyleri yerel etik kurulunca onaylandı (66332047604.01.02-3).

\section{İstatistiksel Analiz}

İstatistiksel analiz Statistical Packages for the Social Sciences (SPSS Inc. Chicago, IL, USA) 21.0 programı ile yapıldı. Numerik veriler ortalama ve standart sapma ve median olarak verildi. Gruplar Kruskall-Wallis testi ile karşılaştııldı. Ikili grupların Posthoc analizi Mann-Whitney-U testi ile yapıldı. Verilerin korelasyon analizi Spearman's korelasyon testi ile yapıldı. $\mathrm{p}<0.05$ istatistiksel olarak anlamlı kabul edildi.

\section{BULGULAR}

Kan kreatinin düzeyi böbrek fonksiyonlarının göstegesi olarak kabul edildi. İskemi/Reperfüzyon hasarı oluşturulan gruplarda (IR/Se ve IR/0) kan kreatinin düzeyindeki artıss sham grubu ile karşılaştııılığında anlamlıydı ( $p=0.027)$. Il ginç bir şekilde IR/Se grubunda kan kreatinin düzeyi IR/0 grubundan yüksekti, ancak bu yükseklik istatistiksel anlamlı değildi ( $p=0.053)$.

Serum total thiol, nativ thiol, disülfid ve thiol/disülfid oranları hücrenin oksidatif göstergeleri olarak kabul edildi. IR/O grubunda cerrahi prosedür öncesi ve sonrası total thiol düzeyinde belirgin düşme gözlendi; cerrahi prosedür öncesi total thiol düzeyi $329.05 \pm 24.09 \mathrm{mmol} / \mathrm{L}$ iken IR hasarı sonrası $181.9 \pm 20.71 \mathrm{mmol} / \mathrm{L}$ olarak saptandı $(p=0.028)$. IR/Se grubu değerlendirildiğinde IR hasarı öncesi total thiol 314.68 \pm 22.72 $\mathrm{mmol} / \mathrm{L}$ iken cerrahi prosedür sonrası $283.77 \pm 52.63 \mathrm{mmol} / \mathrm{L}$ olarak ölçüldü, total thiol seviyesinde istatistiksel anlamlı değişim görülmedi ( $p=0.345)$. Benzer şekilde nativ thiol düzeyleri de IR/ Se grubunda anlamlı azalma göstermedi. İskemi/Reperfüzyon hasarı sonrası IR/Se ve IR/O grupları thiol/disülfid oranı açısından karşılaştııılı̆ğında Se tedavisi alan grupta thiol/

Tablo I: Grupların kan kreatinin, total thiol, nativ thiol ve dinamik thiol/disülfid oranları.

\begin{tabular}{|c|c|c|c|c|}
\hline Gruplar & $\begin{array}{c}\begin{array}{c}\text { Kreatinin } \\
\text { (mg/dl) }\end{array} \\
\end{array}$ & $\begin{array}{c}\text { Total Thiol } \\
(\mathrm{mmol} / \mathrm{L})\end{array}$ & $\begin{array}{l}\text { Nativ Thiol } \\
(\mathrm{mmol} / \mathrm{L})\end{array}$ & Thiol/Disülfid Oranı \\
\hline iR (1) & $0.4 \pm 0.04$ & $329.05 \pm 24.09$ & $195.55 \pm 22.31$ & $13.45 \pm 1.95$ \\
\hline iR (2) & $1.17 \pm 0.12$ & $181.90 \pm 20.71$ & $130.35 \pm 17.74$ & $9.8 \pm 2.25$ \\
\hline $\mathbf{p}^{*}$ & 0.040 & 0.028 & 0.035 & 0.032 \\
\hline IR/Se (1) & $0.5 \pm 0.8$ & $314.68 \pm 22.72$ & $156.38 \pm 15.4$ & $24.05 \pm 14.23$ \\
\hline iR/Se (2) & $3.07 \pm 1.17$ & $283.77 \pm 52.63$ & $131.02 \pm 46.7$ & $18.52 \pm 3.56$ \\
\hline $\mathbf{p}^{\dagger}$ & 0.028 & 0.345 & 0.478 & 0.337 \\
\hline $\mathbf{p}^{\ddagger}$ & 0.053 & 0.033 & 0.337 & 0.004 \\
\hline
\end{tabular}

iR (1): Salin tedavisi alan iskemi/Reperfüzyon grubu, cerrahi öncesi, iR (2): Salin tedavisi alan iskemi/Reperfüzyon grubu, reperfüzyon sonrası, iR/ Se (1): Selenyum tedavisi alan iskemi/Reperfüzyon grubu, cerrahi öncesi, iR/Se (2): Selenyum tedavisi alan iskemi/Reperfüzyon grubu, reperfüzyon sonrası. $\boldsymbol{p}^{*}$ : Salin tedavisi alan grup (IR/O) işlem öncesi ve sonrası, $\boldsymbol{p}^{+}$: Selenyum tedavisi alan grup (IR/Se) işlem öncesi ve sonrası, $\boldsymbol{p}^{*}$ : Selenyum ve salin tedavisi alan gruplar işlem sonrası

Tablo II: Grupların histopatolojik bulguları.

\begin{tabular}{l|c|c|c|c|c}
\hline & Tübüler epitel ödemi & Tübüler dilatasyon & Epitel nekrozu & Tübüler silendir & Konjesyon \\
\hline iR & - & - & - & - & - \\
\hline IR/0 & ++ & ++ & ++ & ++ & ++ \\
\hline iR/Se & +++ & +++ & +++ & +++ & +++ \\
\hline
\end{tabular}

iR: İskemi/reperfüzyon uygulanmamış olan sağ nefrektomi materyali, iR/O: Salin ile tedavi edilen grup iskemi/reperfüzyon hasarlı sol nefrektomi materyali, iR/Se: Selenyum ile tedavi edilen grup iskemi/reperfüzyon hasarlı sol nefrektomi materyali. 
disülfid oranı $18.52 \pm 3.56$ iken IR/0 grubunda $9.8 \pm 2.25$ olarak ölçüldü ( $p=0.004)$. Bu durum Se tedavisinin anlamlı derecede hücre redoksunu iyileștirdiğini göstermektedir. Tüm grupların biyokimyasal sonuçları tablo l'de özetlenmiştir.

Gruplar histopatolojik açıdan karşılaştııılı̆ğında Se tedavisi alan grupta histopatolojik değişikliklerin daha şiddetli olduğu görüldü. Grupların histopatolojik bulguları tablo Il'de özetlenmiștir.

\section{TARTIŞMA}

İskemi/Reperfüzyon hasarı nativ ve nakil böbrekte akut böbrek hasarını en önemli sebeplerinden biridir. Akut böbrek hasarı, glomerüler ve tübüler hasar ile ilişkili olarak glomerüler filtrasyon hızının azalması, oligoüri ve üremik toksinlerin birikimiyle karakterizedir (10). Burada glomerüler ve tübüler hasar özellikle dokuların re-oksijenizasyonu sırasında artan rOR ile ilişkilidir. Reaktif oksijen radikalleri hücrenin hemen tüm komponentleriyle reaksiyona girerek hücrede yapısal ve fonksiyonel hasara neden olur (11). Thioller, doku ve organizmayı rOR'nin etkilerine karşı koruyan önemli anti-oksidan organik yapılardır (12). Yapılan çalısmalarda IR hasarı sürecinde thiol miktarında belirgin azalma olduğu gösterilmiştir (12,13). Selenyum anti-oksidan sistemlerde etkin bir eser elementtir. Anti-oksidan etkisi oksidan/antioksidan sistemin düzenlenmesi ve tamponlanmasıdır $(14,15)$. Bundan dolayı çeşitli doku ve organlarda gelişen IR hasarında Se tedavisinin etkisi özel bir ilgi konusudur.

Ostadalova ve ark. (16), Se desteğinin 10-günlük ratlarda iskemi sonrası kardiyak kontraktilitenin düzelmesinde etkili olduğunu göstermiştir. Benzer şekilde yetişkin ratlarda da Se desteği IR hasarının kalp üzerindeki etkilerini azaltmaktadır (17). Hasanvand ve ark. (18) yapmış oldukları bir çalışmada 2 hafta boyunca $0.2 \mathrm{mg} / \mathrm{kg}$ intra peritoneal Se tedavisi uyguladıkları ratlarda, IR hasarı sonrasında renal biyokimyasal ve histopatolojik hasarlanmanın Se tedavisi almayan ratlara kıyasla daha hafif olduğunu göstermişlerdir. Bu çalışmadan farklı olarak çalıșmamızda iki doz $0.625 \mathrm{mg} / \mathrm{kg}$ Se tedavisi oral olarak uygulandı. Kısa süreli akut Se tedavisi ile renal dokuda oksidatif durumun olumlu etkilendiğini göstermekle birlikte tedavi alan ratlarda kan kreatinin düzeyinin istatistiksel anlamlı olmasa da daha yüksek olduğunu ve histopatolojik etkilenimin daha ağır olduğunu gördük. Bu durumun Se tedavisinin yüksek dozuyla ilişkili olabileceği düşünülebilir. Ancak Rendjelovic ve ark. (19) yapmış oldukları bir çalışmada 9 gün süresince $1 \mathrm{mg} / \mathrm{kg} \mathrm{Se}$ tedavisi uygulanan ratlarda gentamisin ilişkili nefrotoksisite gelişiminin Se tedavisi almayan ratlara oranla azalmış olduğunu göstermişlerdir. Bu açıdan değerlendirildiğinde çalışmamızda yeterli biyokimyasal iyileşmenin görülmemesi doz ilişkili olmaktan ziyade süre ile ilişkili olarak değerlendirilebilir. Literatürdeki çalısmaları da değerlendirdiğimizde renal doku söz konusu olduğunda uzun vadeli Se tedavisinin renal biyokimyasal ve histopatolojik olumlu etkileri görülmektedir (18-21). Öte yandan çalışmamızda Se tedavisi yukarıdaki çalışmalardan farklı olarak intra peritoneal değil oral olarak verilmiştir. Bu durumda Se tedavisinin yeterli etkinlik sağlayacak kan düzeyine ulaşmadığı düşünülebilir. Ancak çalışmamızda yeterli anti-oksidan etkinlik gösterilmişti, bu durum oral tedavi ile yeterli Se kan düzeyine ulaşıldığını göstermektedir.

İskemi/Reperfüzyon ilişkili akut böbrek hasarı, renal tübüler inflamasyon, tübül epitel hücrelerinin ödemlenmesi, nekroze olması ve dökülmesi, tübüllerde tıkanıkık oluşturmasıyla karakterizedir (22). Çalışmamızda IR hasarına maruz bırakılan ratlarda tübüler hasarlanma bulguları görüldü, Se tedavisi alan ratlarda tedavinin histopatolojik olumlu etkisi gösterilemedi. Illginç şekilde Se tedavisi alan ratlarda IR sonrası oluşan histopatolojik bulgular salin alan ratlardan daha belirgindi. Öztürk ve ark. (23) intestinal IR hasarı oluşturulan ratlarda, iskemi öncesi Se tedavisinin antioksidan, biyokimyasal ve histopatolojik olumlu etkileri olduğunu göstermiştir. Çalışmamızda 2. doz Se, 4 saatlik reperfüzyon sonrası uygulanmıştır. Bu durum Se tedavisinin halihazırda hasarlı böbrekte toksik etki yaptığını dolayısıyla kurtarıcı bir tedavi olarak özellikle reperfüzyon sonrası uygulanmasının olumsuz etkileri olacağını düşündürmektedir.

IR hasarı sonrası değişen dozlarda tek doz Se tedavisinin etkileri değerlendirildiğinde, farklı doku ve organlarda değişen sonuçlar elde edilen çalışmalar dikkati çekmektedir. Akman ve ark. (24) intussussepsiyon ilişkili IR hasarı oluşturdukları deneysel bir modelde, $0.2 \mathrm{mg} / \mathrm{kg}$ tek doz Se tedavisinin intestinal redoksu olumlu yönde etkilediğini ancak histopatolojik değişiklikler üzerinde etkisiz olduğunu göstermişslerdir. Bu çalışmada histopatolojik düzelme görülmemesi, benzer çalışmalardan farklı olarak mezenterik arter klemplenmeksizin IR hasarının mekanik olarak oluşturulmasına ve dolayısıyla diğer çalışmalardan daha ağır histopatolojik hasar gelișmiş olmasına bağlanmıştır. Ancak biz çalışmamızda antioksidan iyileşmeye karşın yeterli histopatolojik iyileşme görülmemesini, doku düzeyindeki cevabın gelişmesi için sürenin yetersiz olmasıyla da ilişkili olabileceğini düşünmekteyiz. Buna karşın Avlan ve ark. (25) ve Bozkurt ve ark. (26) ise $0.2 \mathrm{mg} / \mathrm{kg}$ tek doz Se tedavisinin IR hasarı olușturulmuş rat testis ve over dokusunda hücre redoksunda ve histopatolojik düzeyde olumlu etkisini aynı anda gözlemlemişlerdir. Bu durum çeșitli doku ve organların IR hasarına duyarlııklarının, tedavi cevaplarının, iyileşme sürelerinin değişkenliği ile açıklanabilir.

Sonuç olarak, bu aşamada İR hasarı öncesi ve sonrası tek doz Se uygulamasının böbrek dokusu üzerinde redoksu olumlu yönde değiştirdiğini ancak biyokimyasal ve histopatolojik düzeyde etkisiz olduğunu hatta halihazırda hasarlanmış dokuda belirti ve bulguları akut dönemde arttırdığını düşünmekteyiz. Travma, transplantasyon, kardiyovasküler cerrahi girişimler gibi nedenlere bağlı olarak gelişen akut renal hasarda, akut kısa süreli Se tedavisinin yerini netleştirmek açısından daha geniş örneklem, değişen dozlar ve sürelerin değerlendirildiği çalışmalar gerekmektedir. 


\section{KAYNAKLAR}

1. Jang HR, Rabb $H$. The innate immune response in ischemic acute kidney injury. Clin Immunol 2009;130:41-50.

2. Baud L, Ardaillou R. Reactive oxygen species: Production and role in the kidney. Am J Physiol 1986;251:1765-76.

3. Halliwell B, Aeschbach R, Loliger L, Aruoma OI. The characterization of antioxidants. Food Chem Toxicol 1995;33:601-17.

4. Şener G, Yeğen BÇ. İskemi Reperfüzyon Hasarı. Klinik Gelişim 2009;22:5-13.

5. Turell L, Radi R, Alvarez B. The thiol pool in human plasma: the central contribution of albumin to redox processes. Free Radic Biol Med 2013;65:244-53.

6. Jones DP, Liang Y. Measuring the poise of thiol/disulphide couples in vivo. Free Radic Biol Med 2009;47:1318-29.

7. Rayman MP. The importance of selenium to human health. Lancet 2000;356:233-41.

8. Erel O, Neselioglu S. A novel and automated assay for thiol/ disulphide homeostasis. Clin Biochem 2014;47:326-32.

9. Korkmaz A, Kolankaya D. Protective effect of rutin on the ischemia/reperfusion-induced damage in rat kidney. J Surg Res 2010;164:309-15.

10. Devarajan P. Update on mechanisms of ischemic acute kidney injury. J Am Soc Nephrol 2006;17:1503-20.

11. Ahmadiasl N, Banaei S, Alihemmati A. Combination antioxidant effect of erythropoietin and melatonin on renal ischemia-reperfusion injury in rats. Iran J Basic Med Sci 2013;16:1209-16.

12. Prakash M, Shetty MS, Tilak P, Anwar N. Total thiols: Biomedical importance and their alteration in various disorders. Online J Health Allied Scs 2009;8:2.

13. Hosseinzadeh $H$, Sadeghnia HR, Ziaee T, Danaee A. Protective effect of aqueous saffron extract (Crocus sativus L.) and crocin, its active constituent, on renal ischemia-reperfusion-induced oxidative damage in rats. J Pharm Sci 2005;8:387-93.

14. Savaşkan NE, Brauer AU, Kühbacher M, Eyüpoğlu IY, Kyriakopoulos A, Ninnemann O, et al. Selenium deficiency increases susceptibility to glutamate-induced excitotoxicity. FASEB 2008;17:112-14.

15. Hondal RJ, Marino SM, Gladyshev VN. Selenocysteine in Thiol/ Disulfide-like Exchange Reactions. Antioxid Redox Signal 2013;18:1675-89.
16. Ostadalova I, Vobecky M, Chvojkova Z, Mikova D, Hampl V, Wilhwm J, et al. Selenium protects the immature rat heart against ischemia/reperfusion injury. Mol Cell Biochem 2007;300: 259-67.

17. Turan B, Saini HK, Zhang M, Prajapati D, Elimban V, Dhalla NS. Selenium improves cardiac function by attenuating the activation of NF-kappa B due to ischemia-reperfusion injury. Antioxid Redox Signal 2005;7:1388-97.

18. Hasanvand A, Abbaszadeh A, Darabi S, Nazari A, Gholami M, Kharazmkia A. Evaluation of selenium on kidney function following ischemic injury in rats; protective effects and antioxidant activity. J Renal Inj Prev 2016;6:93-98.

19. Randjelovic P, Veljkovic S, Stojiljkovic N, Velickovic L, Sokovic D, Stoiljkovic M. Protective effect of selenium on gentamicin-induced oxidative stress and nephrotoxicity in rats. Drug Chem Toxicol 2012;35:141-8.

20. Gunes S, Sahinturk V, Karasati P, Sahin IK, Ayhanci A. Cardioprotective effect of selenium against cyclophosphamideinduced cardiotoxicity in rats. Biol Trace Elem Res 2017;177:10714.

21. Ozbal S, Erbil G, Koçdor H, Tuğyan K, Pekçetin Ç, Özoğul C. The effects of selenium against cerebral ischemia-reperfusion injury in rats. Neurosci Lett 2008;438:265-69.

22. Chatterjee PK. Novel pharmacological approaches to the treatment of renal ischemia-reperfusion injury: a comprehensive review. Naunyn-Schmiedebergs Arch Pharmacol 2007;376: 1-43.

23. Öztürk C, Avlan D, Cinel İ, Cinel L, Ünlü A, Camdeviren H. Selenium Pretreatment Prevents Bacterial Translocation in Rat Intestinal Ischemia/Reperfusion Model. Pharmaco Research 2002;45:171-7.

24. Akman H, Somuncu S, Dikmen G, Ayva Ș, Soyer T, Doğan P. Protective Effect of Selenium on Intussusception-induced Ischemia/Reperfusion Intertinal Oxidative Injury in Rats. Turk J Med Sci 2020;40:391-7.

25. Avlan D, Erdoğan K, Çimen B, Apa DD, Ciner I, Aksöyek S. The Protective Effect of Selenium on Ipsilateral and Contralateral Testes in Testicular Reperfusion Injury. Pediatr Surg Int 2005;21:274-8.

26. Bozkurt S, Arikan DC, Kurutaş EB, Sayar H, Okumuş M, Coskun A. Selenium Has a Protective Effect on Ischemia/Reperfusion Injury in a Rat Ovary Model Biochemical and Histopathologic Evaluation. J Ped Surg 2012;47:1735-41. 